\title{
Practices and Needs in Reintegration Programs for Violent Extremist Offenders in the United States: The Probation Officer Perspective
}

\author{
Jessica E Stern, $\mathrm{PhD}$ \\ Harvard T.H. Chan School of Public Health \\ Marley Carroll \\ Harvard T.H. Chan School of Public Health
}

\author{
Megan K McBride, PhD \\ Harvard T.H. Chan School of Public Health \\ Adam Baker \\ Harvard T.H. Chan School of Public Health
}

\author{
Elena Savoia, MD, MPH \\ Harvard T.H. Chan School of Public Health
}

This project was made possible by funding and support from the National Institute of Justice (Applying a Developmental Evaluation Approach to Address Community Safety and Health Challenges of Reintegration Programs in the USA - Award Number 2019-ZA-CX-001). The content of this manuscript as well as the views expressed therein are solely those of the authors and do not necessarily represent the official views of NIJ, nor does mention of trade names, commercial practices, or organizations imply endorsement by the U.S. government.

\section{Introduction}

In 2018, it was reported that 108 federal inmates with a history of violent extremism including both involvement with foreign and domestic terrorist organizations - were scheduled to be released over the next five years. ${ }^{1}$ While this number alone is cause for concern, it is important to note that this is a federal number. As such, it does not capture domestic violent extremists (DVEs) who committed crimes unrelated to their involvement in a DVE group or movement — as often happens with antigovernment or anti-authority violent extremists (AGAAVEs) and racially or ethnically motivated violent extremists (RMVEs) — and who were consequently charged and convicted in state courts. Moreover, there is no comprehensive

\footnotetext{
${ }^{1}$ Kevin D. Lowry, "Responding to the Challenges of Violent Extremism/Terrorism Cases for United States Probation and Pretrial Services," Journal for Deradicalization 17 (Winter 2018/2019): 28-88.
} 
database documenting (a) the full range of lethal and nonlethal activity conducted by extremists across the country or (b) the true number of extremists currently in state and federal custody. ${ }^{2}$ This number consequently represents an unknown percentage of recently- or soon-to-be-released inmates with a history of violent extremism.

What is clear, though, is that the number is likely to increase. According to the Office of the Director of National Intelligence (ODNI), the narratives questioning the legitimacy of the 2020 presidential election combined with the pandemic and violence-promoting ideologies will likely spur additional violence. ${ }^{3}$ On March 2, 2021, FBI Director Christopher Wray reported that over the past two years, the number of domestic terrorism investigations being pursued by the FBI has increased from 850 to approximately $2,000 .{ }^{4}$

The likely increase in the number of DVEs in prison and on probation poses a particular concern because there is little guidance or knowledge on how best to reintegrate this population. Many countries around the world have developed deradicalization and reintegration programs, some of which are initiated while subjects are still in prison, and others after they are released. However, in the United States, the Probation and Pretrial Services system has not yet developed formal strategies for disengagement and rehabilitation for individuals incarcerated for terrorismrelated crimes. ${ }^{5}$ Minnesota has experimented with reintegration programming for jihadi offenders, but the program is still at an experimental stage. Kevin Lowry, former chief probation officer for the U.S. District Court of Minnesota, describes Minnesota's programming as an

\footnotetext{
${ }^{2}$ U.S. Department of Justice, Federal Bureau of Investigation, Domestic Terrorism: Definitions, Terminology, and Methodology (November 2020).

${ }^{3}$ U.S. Office of the Director of National Intelligence, U.S. Department of Justice, and U.S. Department of Homeland Security, Unclassified Summary of Assessment on Domestic Violent Extremism (March 17, 2021).

${ }^{4}$ U.S. Congress, Senate, Judiciary Committee, Oversight of the Federal Bureau of Investigation: The January 6 Insurrection, Domestic Terrorism, and Other Threats, 117th Cong., 1st sess., March 2, 2021.

${ }^{5}$ Lowry, "Responding to the Challenges of Violent Extremism/Terrorism Cases."
} 
"experimental lab" and "training hub" for developing cutting-edge practices that can be applied to cases of extremism in the United States. ${ }^{6}$

The need for such programming, though, is clear. Criminologists have long argued that prisons, rather than places of rehabilitation, can be spaces where offenders become more deeply committed to a culture of crime through a process known as prisonization. ${ }^{7}$ Prison can also expose incarcerated offenders to previously unencountered terrorist ideologies, leading some to accept violence is a legitimate way to achieve ostensibly political goals. Gary LaFree, Bo Jiang, and Lauren C. Porter examined the link between imprisonment and participation in violent extremism. They found that prison time increases the probability that political extremists would become violent and that prison-based radicalization further increases the probability of violence. ${ }^{8}$ The authors concluded that because spending time in prison is a predictor of engaging in violent extremist behavior, efforts to steer at-risk youth away from crime and time in prison should be encouraged. A number of nonprofit organizations are now attempting to address this issue. For example, the Citizens Crime Commission's Disruption and Early Engagement Program (DEEP), based in New York City, is providing law enforcement agencies with specialized behavioral interventions that can be utilized at any stage of the criminal justice system, from pre-arrest to post-conviction. ${ }^{9}$

A study by Scott Decker and David Pyrooz explored whether time in prison increased activism (legal and nonviolent forms of political mobilization) or radicalization. ${ }^{10}$ They found

\footnotetext{
${ }^{6}$ Lowry, "Responding to the Challenges of Violent Extremism/Terrorism Cases."

${ }^{7}$ Nader Naderi, "Prisonization," in The Encyclopedia of Criminology and Criminal Justice, ed. Jay S. Albanese (Oxford: Blackwell Publishing Ltd., 2014), 1-5.

${ }^{8}$ Gary LaFree, Bo Jiang and Lauren C. Porter, "Prison and Violent Political Extremism in the United States," Journal of Quantitative Criminology 36 (2020): 473-498.

${ }^{9}$ U.S. Congress, House, Committee on Appropriations, Subcommittee on the Department of Homeland Security, Targeted Violence and Terrorism Prevention, 117th Cong., 1st sess., March 24, 2021.

${ }^{10}$ Sophia Moskalenko and Clark McCauley, "Measuring Political Mobilization: The Distinction Between Activism and Radicalism," Terrorism and Political Violence 21, no. 2 (March 30, 2009): 239-260.
} 
that though the releasees' level of activism decreased, their level of radicalization was unchanged. Decker and Pyrooz hypothesize that nonviolent activism decreased because, unlike radicalization, it requires commitment of time and capital. ${ }^{11}$ Consistent with these findings, the National Counterterrorism Center (NCTC) warned that some individuals convicted of terrorismrelated crimes "will probably reengage in terrorist activity" upon their release, suggesting that for some extremists, prison time is not rehabilitative. ${ }^{12}$ Decker and Pyrooz ultimately propose that there is an important role for programming that keeps released inmates engaged in prosocial activities and strengthens prosocial relationships and beliefs. ${ }^{13}$

\subsection{The effectiveness of deradicalization and reintegration programming}

In 2017, RAND published a study indicating that there were "only eight sources that assessed the impact of CVE programming." ${ }^{14}$ We conducted a literature review, hoping to find that this number had increased since 2017. Our initial search identified nearly 275 pieces of literature (peer-reviewed articles and gray literature) related to reintegration programs for extremists; this was, however, pared down to approximately 30 articles when a stricter filterrequiring the article to evaluate a specific program — was introduced. Though this appeared to be a promising increase, closer analysis made clear that few of the articles (less than 15 percent) were the kind of formal, rigorous, and independent evaluations upon which future program designers could confidently rely. In other words, though deradicalization and reintegration

\footnotetext{
${ }^{11}$ Scott H. Decker and David C. Pyrooz, "The Imprisonment-Extremism Nexus: Continuity and Change in Activism and Radicalism Intentions in a Longitudinal Study of Prisoner Reentry,” PLoS ONE 15, no. 11 (2020), https://doi.org/10.1371/journal.pone.0242910.

${ }^{12}$ U.S. Office of the Director of National Intelligence, National Counterterrorism Center, "US Homegrown Violent Extremist Recidivism Likely," National Counterterrorism Center Current (January 24, 2017).

${ }^{13}$ Decker and Pyrooz, "The Imprisonment-Extremism Nexus."

${ }^{14}$ Sina Beaghley et al., "Development and Pilot Test of the RAND Program Evaluation Toolkit for Countering Violent Extremism," RAND Corporation (2017).
} 
programming has expanded over the last two decades, there is still a troubling paucity of work assessing what works and what doesn't. This is especially concerning because, as one scholar warned, ill-designed and ineffective deradicalization or disengagement programs can increase the risk of terrorism by failing to detect high-risk cases. ${ }^{15}$

Unfortunately, the majority of the studies we identified offered something closer to general analysis than actual evaluation, providing overarching descriptions of the environments in which these programs operated, outlining the characteristics of the programs themselves, and examining the theoretical underpinnings on which the programs rested. ${ }^{16}$ While all of these studies are important to help us understand what reintegration efforts are happening worldwide and how they are implemented, there is little doubt that important questions remain unanswered.

\subsection{Study aims}

Our project sought to accomplish two objectives. First, we aimed to understand the full set of resources available to federal probation officers tasked with supervising extremist offenders. In answering this question, we aimed to identify: 1) services and practices that federal probation officers utilize when managing extremist offenders and 2) probation officers' needs as they relate to supervising this population. This article is consequently distinct from most of the literature because instead of focusing on a single program (e.g., EXIT) or a single program

\footnotetext{
15 Daniel Koehler, "How and Why We Should Take Deradicalization Seriously," Nature Human Behaviour 1 (2017): 1-4.

${ }^{16}$ Chaula Rininta Anindya, "The Deradicalisation Programme for Indonesian Deportees: A Vacuum in Coordination," Journal for Deradicalization 18 (Spring 2019): 217-243; Douglas Weeks, "Doing Derad: An Analysis of the U.K. System," Studies in Conflict \& Terrorism 41, no. 7 (2018): 523-540; Zubair Azam and Syeda Bareeha Fatima, "Mishal: A Case Study of a Deradicalization and Emancipation Program in Swat Valley, Pakistan," Journal for Deradicalization 11 (Summer 2017): 1-29; D. Sestoft, S.M. Hansen, A.B. Christensen, “The Police, Social Services, and Psychiatry (PSP) Cooperation as a Platform for Dealing with Concerns of Radicalization," International Review of Psychology 29, no. 4 (2017): 350-354; Mehmet F. Bastug and Ugur K. Evlek, "Individual Disengagement and Deradicalization Pilot Program in Turkey: Methods and Outcomes," Journal for Deradicalization 8 (Fall 2016): 25-45; Judy Korn, "European CVE Strategies from a Practitioner's Perspective," Annals of the American Academy of Political and Social Science 668, no. 1 (2016): 180-197.
} 
component (e.g., job training), it attempts to capture the full range of services and resources available to federal probation officers working to reintegrate extremists (which could include access both to programs and to a range of program components).

Second, we aimed to identify which current practices for managing extremist offenders released from U.S. prisons would benefit from an evaluation. It is important to avoid conducting evaluations before having a clear understanding of what components of a program are evaluable as researchers sometimes discover that a program is not ready to be evaluated after the evaluation has already begun. Thus, our study also includes an evaluability assessment, which is the process of identifying whether an evaluation is "justified, feasible, and likely to provide useful information." ${ }^{17}$ We collected data from U.S. probation officers currently engaged in the work of reintegrating extremist offenders to understand what interventions within current reintegration efforts are suitable for a more in-depth evaluation.

\section{Methods}

We used a mixed-methods approach, combining qualitative data derived from interviews with quantitative data derived from a survey, to describe the types of services and practices used by federal probation officers in the management of extremist offenders. ${ }^{18}$ All data collection instruments and processes were approved by the Harvard Chan School Institutional Review Board protocol number 19-1703.

\footnotetext{
${ }^{17}$ Deborah Kaufman-Levy and Mary Poulin, "Evaluability Assessment: Examining the Readiness of a Program for Evaluation,” Juvenile Justice Evaluation Center Program Evaluation Briefing Series, 6 (May 2003): 5, https://www.jrsa.org/pubs/juv-justice/evaluability-assessment.pdf.

${ }^{18}$ Barbara Bowers et al., "Creating and Supporting a Mixed Methods Health Services Research Team," Health Services Research 48, no. 6 part II (2013), doi:10.1111/1475-6773.12118.
} 


\subsection{Interviews}

Interviews were conducted with federal probation officers and in some cases with the released offenders under their supervision using the convergent interviewing technique, which seeks to balance broad versus specific questions. Through this semi-structured approach, information is analyzed in a step-by-step process and relevant information obtained from earlier interviews is used to develop more probing questions for later interviews. Thus, the interview process becomes more structured with each subsequent interview. This method encourages storytelling on the part of the interviewee, ensuring that the interview is guided more by the participant than the researcher. Interview questions focused on the officer's background and caseload, risk assessment tools, monitoring techniques, availability of specific services for their clients, and the officer's training needs. Interviewees were recruited with support from federallevel supervisors, who, when contacted by our team, disseminated an email from our team to the federal probation officers within their networks. When possible, the officers who agreed to be interviewed invited the released offenders they were supervising to be interviewed by us. This approach allowed us to learn about the case management process from both the officers' and clients' perspectives. All interviews were conducted between June 2020 and April 2021 via Zoom and none were recorded. All interviewers had prior experience researching violent extremism. Sample size was based on reaching theoretical thematic saturation, the point at which new data confirmed the analysis and no longer offered any new information.

\subsection{Interview data analysis}

Two team members took notes during each interview. After interviews, notes were compared, combined, and deidentified. The note takers removed both the names and specific 
locations of individuals mentioned during the interview to preserve anonymity while retaining the essential components of the narrative. General terms, such as "the state in which the interviewee practiced" or "the extremist group that the client was affiliated with" were substituted in place of specific descriptors and names that were present in the initial interview notes. Systematic coding procedures were adopted to analyze the data. Systematic coding involves reading interview transcripts and assigning codes that reflect both broad themes and finer distinctions within each theme. The analysis entailed intensive reading of the text and discussion between analysts, followed by coding and thematic formulation processes leading to the creation of a structured, hierarchical database index using the software NVivo 12.

\subsection{Survey}

Based on the initial results of the interviews, we designed an online survey to expand the data collection to a broader network of federal probation officers and to validate the results of the interviews. The survey was designed for officers with and without experience overseeing violent extremist offenders in order to compare how officers manage extremist versus non-extremist offenders. Like the interviews, the survey addressed topics such as risk assessment tools, monitoring techniques, availability of specific services for their clients, and training needs. The survey was implemented between April and June 2021. Descriptive statistics were computed and integrated with the results of the interviews as reported below.

\section{Results}

Over the course of our study, we interviewed a total of 39 federal probation officers across 27 districts. The officers had experience working with racially or ethnically motivated 
violent extremists (RMVEs), antigovernment or anti-authority violent extremists (AGAAVEs), jihadi violent extremists, and sovereign citizens. Many also had experience working with other high-risk offenders, including sex offenders and gang members. The nature of the crimes ranged from liminal cases in which the client's involvement in extremist activity was unclear, to highprofile terrorism-related, violent crimes.

We gathered survey responses from a sample of 206 officers, $73 \%$ (150) of whom had experience overseeing violent extremists. Slightly more than half (55\%) of the respondents who managed violent extremists had more than ten years of experience in federal probation, and approximately one quarter of those who had managed extremists (24\%) had managed several violent extremist offenders throughout their careers.

Five main themes emerged from the analysis of the data: 1. Risk Assessment and Release Requirements; 2. Training and Support; 3. Approach and Techniques; 4. Client Services; and 5. Outcomes. These themes, and relevant sub-themes, are discussed in detail below and presented in Figure 1. 
Figure 1: Reintegration case management themes and subthemes
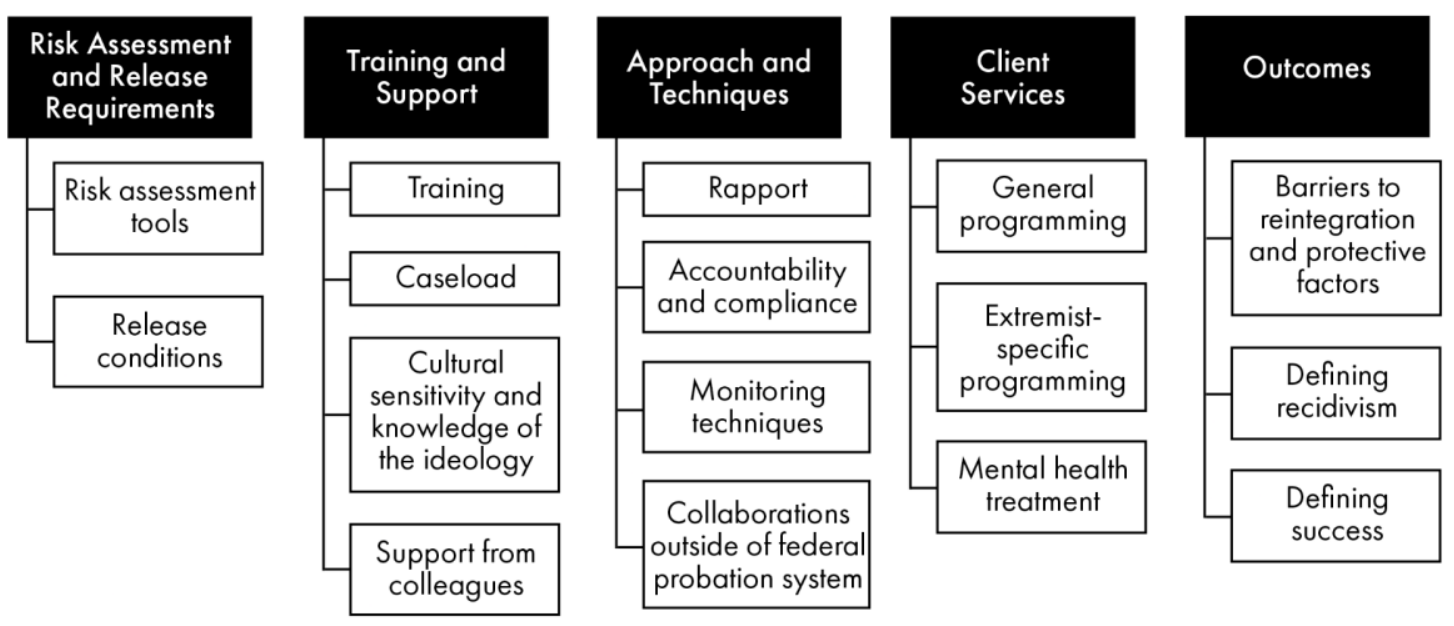

\subsection{Risk Assessment and Release Requirements}

\subsubsection{Risk assessment tools}

The Post Conviction Risk Assessment (PCRA), a tool used to evaluate the risk of

recidivism for new criminal conduct or for an arrest for a violent offense, was mentioned in the majority of interviews. ${ }^{19}$ Almost $70 \%$ of the federal probation officers who mentioned the PCRA discussed overriding the results (using a discretionary override) to compensate for their perception that the PCRA, designed to evaluate the risk of recidivism for common criminals, would underestimate the risks posed by extremist offenders. ${ }^{20}$ Some interviewees specified white

\footnotetext{
${ }^{19}$ Christopher T. Lowenkamp, Alexander M. Holsinger, and Thomas H. Cohen, "PCRA Revisited: Testing the Validity of the Federal Post Conviction Risk Assessment (PCRA)," Psychological Services 12, no. 2 (2015): 149157, https://doi.org/10.1037/ser0000024.

${ }^{20}$ For especially dangerous offenders, probation officers are allowed to override the results. There are two types of overrides available to probation officers. Policy overrides are available when the offender is in a specified category of high-risk offenders. These include sex offenders, persistently violent offenders, offenders with severe mental illness, and youthful offenders with extensive criminal histories. Discretionary overrides are used when the offender
} 
supremacists and antigovernment extremists, including sovereign citizens, as offender types for whom the PCRA may be less accurate. Multiple officers suggested the need for extremistspecific indicators to be added to the PCRA. However, they did not specify what information the indicators would capture. Another interviewee emphasized the importance of frequently updating PCRA results in response to major events in offenders' lives, such as violations of probation or changes in personal life (e.g., getting married) or employment status (e.g., finding or losing a job). One officer stated that frequent updates will "naturally move [the offender] up or [down] on the PCRA" if necessary. Similarly, a different officer discussed lowering the PCRA score of an offender when there were indications of stability and growth.

Extremist-specific risk assessment tools came up in only two interviews. Officers mentioned the use of the Extremism Risk Guidelines (ERG22+) and the Violent Extremism Risk Assessment Version 2 Revised (VERA-2R). They indicated that the ERG22+ can account for unique factors that the PCRA may not address, but also noted that it takes a long time to administer and that its performance has not been validated due to insufficient sample size.

\subsubsection{Release conditions}

Discussion of release conditions centered on inconsistency within and across districts. Release conditions included: digital restrictions, mandated volunteer work, mental health counseling, and location monitoring. Multiple interviewees indicated that there is little institutional support for implementing the release conditions for extremist offenders (e.g., inadequate linguistic help to translate online activities in a foreign language), and that there was

does not fall into a specified category, but the officer nonetheless believes that more intensive supervision is required. See Thomas H. Cohen, Bailey Pendergast, and Scott W. VanBenschoten, "Examining Overrides of Risk Classifications for Offenders on Federal Supervision," Federal Probation: A Journal of Correctional Philosophy and Practice 80, no. 1 (June 2016), https://www.uscourts.gov/federal-probation-journal/2016/06/examiningoverrides-risk-classifications-offenders-federal. 
no programming specific to extremist offenders. Another interviewee stated that release conditions "vary by district," and that they "don't get any guidance from [their] agency." This interviewee also pointed to the lack of coordination between districts as a significant barrier to monitoring the released offenders, explaining that "the conditions imposed on offenders are written by the district in which the crime takes place but are enforced where the person lives," which may complicate enforcement. Interviewees identified mental health counseling, digital restrictions, location monitoring, and polygraphs as particularly useful release conditions. More details on monitoring techniques are described in the section "Case Management Approach and Techniques."

\subsection{Training and Support}

Interviewees discussed a number of challenges related to training, support, and collaboration including insufficient time and resources, unfamiliarity with the cultures and ideologies of extremist offenders, and language barriers.

\subsubsection{Training}

In approximately $35 \%$ of interviews, interviewees expressed support for tools and initiatives that they believe would be beneficial but that they currently lack. Extremist-specific initiatives, such as deradicalization programs, were among the most consistently referenced elements in this section. This prevalence echoes sentiments regarding a lack of extremist-specific programming (discussed in more detail in section 3.4 Client Services). That said, officers also indicated, both in interviews and in the survey, that they wanted more training to manage these offenders better. Overall, officers expressed that they were insufficiently prepared to manage violent extremist cases. One officer aptly stated, "we are, with extremists, where we were with 
sex offenders twenty years ago," suggesting that specialized risk assessment tools, together with targeted release conditions and programming, would enable probation officers to manage these clients more effectively. ${ }^{21}$

\subsubsection{Caseload}

Multiple officers mentioned that having a high caseload of high-risk cases inhibits their ability to work closely enough with each individual client, a problem that in some situations is exacerbated by the time spent traveling across large districts to meet with clients. They reported that the caseload in their districts ranged from around 25 to 70 clients per officer, with an average of 50 clients per officer. They found this lack of time especially concerning when working with former violent extremists, whom they saw as requiring more supervision than nonviolent extremist clients.

\subsubsection{Cultural sensitivity and knowledge of the ideology}

Officers also explained how cultural differences can impede communication between officers, their clients, and their clients' families. Unfamiliarity with extremist ideologies unsettled some officers, with one suggesting, "I think there are some advantages to putting [extremists of the same ideology] with the same officer, letting one officer become expert on the topic." Regarding language barriers, one interviewee expressed concern about not being able to tell if a client's foreign language writing contained extremist content.

\subsubsection{Support from colleagues}

Officers also discussed the degree to which they felt that they had adequate support in dealing with this complicated population. Some officers said that they reach out to colleagues in

\footnotetext{
${ }^{21}$ Diána R. Hughes, "Calculating and Managing Risk: Risk Assessment Tools for Violent and Non-Violent Extremist Offenders," submitted in partial fulfillment of the requirements for the degree of Master of International Affairs with a Specialization in Security Studies, Pardee School of Global Studies, Boston University, April 2021.
} 
other districts to seek guidance on how to manage violent extremist offenders. In particular, some officers consulted with colleagues from the District of Minnesota, who have extensive experience in managing these cases. ${ }^{22}$ Interviewees also described periodic meetings with federal probation officers from other districts as a useful method of brainstorming, though they emphasized that collaboration across districts is often challenging because supervision procedures are not standardized. One officer stated, "I think it would be very helpful to have a network of probation officers for sharing information and resources, especially since there are so few extremist cases. It would be nice to have other people's resources but if everyone is doing different things it's hard to determine the right way forward."

\subsection{Approach and Techniques}

\subsubsection{Rapport}

The relationship between probation officers and their clients was discussed in every interview, with a near-universal focus on how to establish rapport and hold clients accountable for their actions. Respect and trust factored into both aims; officers stressed that treating their clients "like a human being" facilitated the communication needed to effectively manage their clients' needs. Many officers suggested that treating the client with respect tends to engender reciprocal respect from the client. Officers also cited honesty and mutual understanding as key facilitators of trust and rapport, with one explaining:

These folks need someone who understands, and can listen, and can comprehend their perspective. They will discount quickly anyone that they think is blowing smoke... who

\footnotetext{
${ }^{22}$ Lowry, "Responding to the Challenges of Violent Extremism/Terrorism Cases," 46.
} 
doesn't seem real or honest. They respect honesty even if they don't like the outcome. They respect officers who are fair and just.

Interviewees emphasized the importance of getting to know their clients' full backgrounds, lives, and beliefs not only in order to assess risk, but also to make their clients feel heard and respected. Officers referenced using the pre-sentence report as a foundation from which to build a relationship with their clients but lamented that "most probation officers go into new cases without having time to get into the weeds [of the case]."

Several interviewees stressed the need to clarify their role as a probation officer, with one officer stating, "Our role is so sensitive....We have to build trust." This role clarification occurs both informally and following processes taught to probation officers through the Staff Training Aimed at Reducing Rearrest (STARR) program, which officers overwhelmingly found helpful. Officers expressed that role clarification encourages clients to trust them and share information with them because it frames officers as clients' allies; the general sentiment shared with the team was "cultivate unity, not just empathy," and that the officer-client relationship should be "a collaborative relationship."

\subsubsection{Accountability and compliance}

In addition to establishing mutual respect and rapport, role clarification also enables probation officers to hold their clients accountable for their actions. One officer conceptualized the officer-client relationship as a contract of sorts, wherein the client needs to be held accountable but in exchange the officer seeks to help them reintegrate into the community rather than playing a punitive role. Few officers discussed specific methods of maintaining client accountability; those that did mentioned various forms of monitoring (communications, social 
media, location), restrictive release conditions, placing concrete responsibilities upon the client, and establishing relationships with the client's family and social network.

Multiple officers commented on how sovereign citizens tend to comply with supervision requirements, though they maintained that sovereign citizens remained radicalized after probation. Many officers questioned the extent to which supervision compliance indicated that their client had disengaged or deradicalized, suspecting instead that many clients complied solely to get off supervised release.

\subsubsection{Monitoring techniques}

Interviewees presented a range of viewpoints on the efficacy of monitoring techniques, but overall support for monitoring was high.

\section{Communications monitoring}

Officers discussed several types of communications monitoring, including digital monitoring, internet monitoring, phone monitoring, social media monitoring, and computer monitoring. Although interviewees generally indicated that computer monitoring can be useful, some mentioned that offenders can find ways to access prohibited digital content through alternative means, so reliance on such monitoring can give officers a false sense of security. One officer suggested that it could be useful to supplement computer monitoring with polygraphs. Some interviewees indicated that they use computer monitoring comparatively less for extremist offenders than for sex offenders. Similarly, one interviewee stated they use location monitoring for sex offenders but not for domestic terrorists.

Officers emphasized that social media monitoring can be difficult to execute when offenders post in foreign languages, and expressed concern about the shortage of personnel trained to conduct social media investigations. Another interviewee praised the utility of limiting 
"places where you can talk to anyone in a way that's not traceable," such as by forbidding access to internet gaming networks. General communication monitoring was mentioned in only four interviews. Multiple probation officers stated that they collaborate on this activity with local or federal law enforcement. Additionally, one of these interviewees emphasized that they engage with a wide variety of individuals during this process, stating that they speak with "significant others, parents, friends, [and] religious clergy" in addition to associates and collateral contacts.

\section{Location monitoring and searches}

Of those interviewees who discussed monitoring techniques, a majority referenced techniques associated with the physical location and space of the offender, such as global positioning system (GPS) monitoring, home searches, and unannounced check-ins. One officer indicated that they have been "aggressive with location monitoring and global positioning systems" and often "push for it with extremist cases." Conversely, a different interviewee was unsure about his district's use of location monitoring for extremist cases, but knew that they had used it for sex offenders. In contrast to the relative prevalence of GPS monitoring, home searches and unannounced check-ins were rarely mentioned.

\section{Substance abuse monitoring}

One third of probation officers who discussed monitoring techniques referenced drugrelated monitoring such as testing. Only one interviewee mentioned drug use in the context of extremism, stating that the overlap of drug use and extremism "makes sense" to him. This interviewee described how young white veterans who "are unable to find jobs or meaning in their lives" may be inclined to gravitate towards extremist groups where "alcohol abuse would be prevalent." 
Similar results were evident in the survey results. Using a scale ranging from 1 (counterproductive) to 5 (very helpful) to indicate the level of usefulness of different types of monitoring techniques, the officers we surveyed indicated that social media monitoring was the most useful technique for monitoring extremist offenders (4.6), followed by home searches (4.48) and drug testing (4.25).

\subsubsection{Collaborations outside of the federal probation system}

Nearly all of the interviewees discussed the importance of collaboration with entities outside the federal probation system. In particular, they mentioned collaboration with other federal agencies, state and local law enforcement, and mental health professionals. Interviewees also discussed collaboration with clients' support systems such as family and friends, faith-based organizations, and local corrections departments, among other entities.

\section{Federal agencies}

Interviewees mentioned collaborating with the Federal Bureau of Investigation (FBI); Bureau of Prisons (BOP); Department of Homeland Security (DHS); Bureau of Alcohol, Tobacco, Firearms, and Explosives (ATF); and Drug Enforcement Administration (DEA). Of these federal partners, collaboration with the FBI, particularly through the local Joint Terrorism Task Force (JTTF), was most common. Officers highlighted collaboration with JTTFs as being especially useful, as the JTTFs "[were] able to gather information because they had access to various databases." One officer referenced the extensive contacts that JTTFs have, recommending, "If you supervise extremists, you should immediately connect with your local JTTF and form as many relationships as you can so that they can begin working with their people." Officers also cited the FBI as a partner for conducting monitoring. Collaboration with 
the BOP mostly consisted of information sharing, with the BOP providing documents to officers regarding their clients' time in prison.

However, a few officers noted the challenges of collaborating with federal agencies, expressing the sentiment that agencies did not sufficiently inform officers about ongoing investigations and that assisting probation officers remained a low priority for federal agencies advancing their own investigations. One officer expressed frustration in working with the FBI, stating, "The FBI doesn't always have respect for probation, I'll be honest with you. We can't always help the FBI the way they want to be helped, so they don't always think of us as teammates, and they don't always tip us in.” Another officer cited federal agencies' secretiveness as a barrier to collaboration. Finally, officers found Witness Security Program (WITSEC) cases to be challenging because they required extreme safeguards and close coordination with federal agencies.

\section{State and local law enforcement}

The primary form of collaboration between probation officers and state and local law enforcement discussed in interviews was information sharing prior to a violent extremist offender's release from prison. Information from state and local law enforcement can also alert officers to potential signs of reengagement. One officer explained, "Collaborative law enforcement constantly has its ear to the ground... probation officers don't have the time to do it. You need your collaborative law enforcement or you won't know what you need to look for," while another officer told the team how "[the officer] had investigative help from local and federal law enforcement... they were like [the officer's] seeing eye dogs." 


\section{Mental health professionals}

When discussing mental health treatment options, some officers mentioned that their districts collaborate with external mental health providers. This form of collaboration entailed both bringing in external providers to run in-house programming and referring clients to contracted mental health professionals. Officers expressed a desire for more extensive collaboration with mental health professionals. However, officers noted a relative dearth of mental health professionals who are both willing and trained to work with extremist clients. One officer told us that some mental-health providers are hesitant to get engaged because they worry about the "high-profile nature of extremist cases." Using a scale ranging from 1 (counterproductive) to 5 (very helpful) to indicate the level of usefulness of different types of collaborations, the officers we surveyed indicated that the collaboration with mental health professional was the most useful (4.3), followed by the collaboration with the client's family members (4.1) and law enforcement agents (3.9). Figure 2 below presents the rating of the survey respondents across a variety of collaborations. 
Figure 2: Federal POs' assessment of the helpfulness of entities and organizations in reintegrating extremist offenders

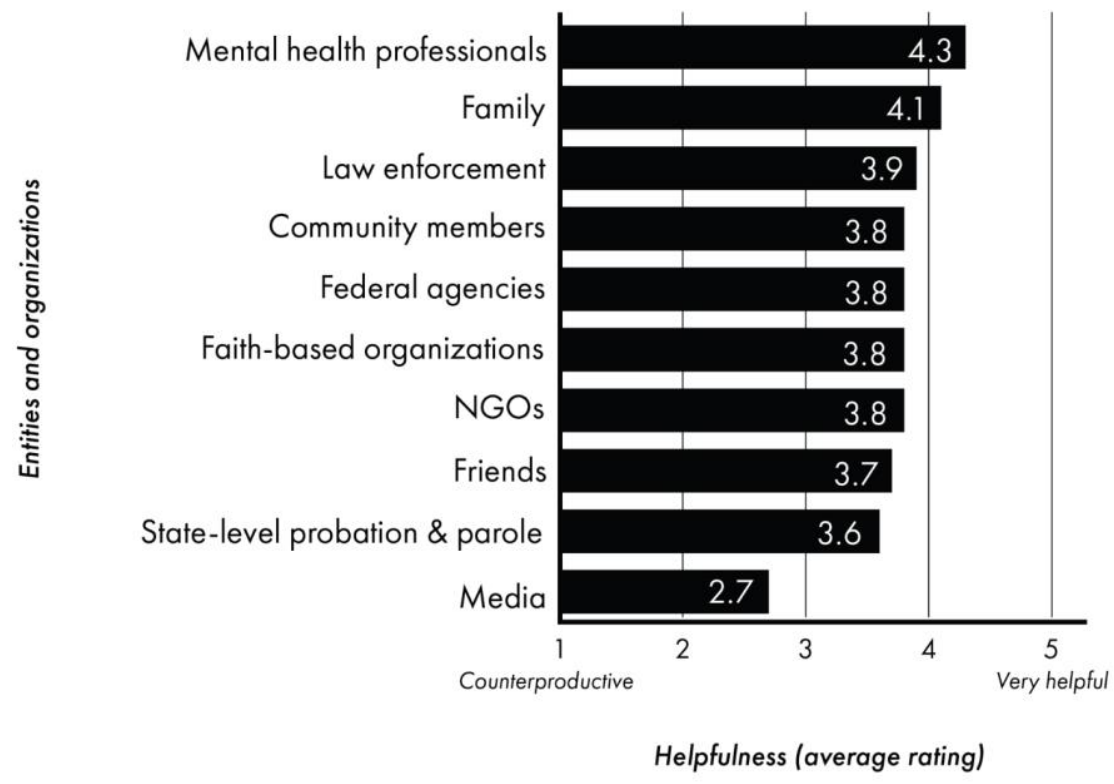

\subsection{Client Services}

The majority of federal probation officers interviewed discussed general supervision programs. Interviewees predominantly focused on substance abuse rehabilitation programs and made comparatively fewer references to other services, such as housing, financial assistance, job training, and educational support. Additionally, an overwhelming majority of probation officers indicated that their districts lacked formal extremist-specific programming, with many interviewees stating that extremist offenders receive either ad-hoc programs or no specialized programs at all.

\subsubsection{General programming}

Substance abuse rehabilitation 
The interviewees who mentioned substance abuse rehabilitation indicated that these services are available to their clients through either government-based programs or external contractors. The only program specified by name was the Residential Drug Abuse Program (RDAP), a treatment initiative provided by the Bureau of Prisons that may enable the reduction of an enrollee's sentence upon successful completion. RDAP was discussed in two interviews. Only one interviewee discussed RDAP at length, claiming that clients typically respond well to its programming and describing how many violent extremist offenders enroll in the program despite being ineligible for the possible sentencing reduction. However, this interviewee also highlighted the importance of correct assessments as he witnessed an antigovernment extremist with a severe heroin addiction who "received no treatment for substance abuse while on probation because the assessment did not recommend it." A different interviewee praised their district for its "treatment opportunities and a rehabilitative mindset," but acknowledged that other districts "don't have [the] luxury" of being able to quickly place offenders into substance abuse rehabilitation programs.

\section{Housing, financial aid, and job training}

Housing assistance was not a prominent theme in discussions about general supervision. The interviewees who mentioned housing assistance or halfway house placement, spoke of these residential assistance methods in combination with other types of support, such as employment assistance and community integration. However, a larger proportion of interviews referenced government financial assistance, particularly in the form of Second Chance Funds. Interviewees indicated that they use these funds to cover the cost of a variety of client services, including tattoo removal, medications, housing, and food. Additionally, one probation officer stated that their district has "started to broaden [their] scope... [by] using these [Second Chance] funds for 
employment and vocational training." Several probation officers indicated that they assist their clients with job training and finding employment. One officer, speaking to the importance of employment as a stabilizing factor in the reintegration process, stated that they "bring employers in [to prisons]" to meet with clients, and that their "revocation rates are a lot lower because of this." Unlike job training, education was seldom mentioned by probation officers, appearing only in two interviews.

\subsubsection{Extremist-specific programming}

In nearly $80 \%$ of all interviews that discussed general supervision programming, interviewees indicated a lack of specific programming for extremist offenders. While officers reported varying levels of access to resources across districts, the lack of extremist-specific programming was a consistent complaint. For instance, one interviewee described themself as not "hav[ing] access to a lot of social services to begin with," and another stated that they "have a rich range of programs by contracted service providers," yet both indicated that they still lacked extremist-specific programming. However, the interviewees did not provide detail regarding what types of extremist-specific programming would be helpful.

\subsubsection{Mental health treatment}

Mental health treatment was discussed in nearly all the interviews. The overwhelming majority of interviewees referenced cognitive behavioral therapy (CBT) and CBT-informed practices, with roughly two-thirds also discussing moral reconation therapy (MRT), a type of CBT. Officers overwhelmingly supported the use of CBT, while MRT received mixed reviews. Other topics discussed were psychotropic medication, access to mental health treatment, and one-on-one therapy with external providers.

\section{Cognitive Behavioral Therapy (CBT)}


Some interviewees mentioned sending clients to outside CBT providers, including both contracted mental health professionals and free community programming. Officers expressed mixed opinions about these outside providers, specifically noting that the efficacy of contracted CBT often depends on the provider's approach. However, officers said that CBT-informed practices helped clients improve their decision-making and curbed criminal thinking styles. One officer explained, “CBT is useful but you can't force it. We use the cognitive model in talking them through decisions. They're typically very impulsive people. They follow their knee jerk reactions. Their reactions are often extreme.” A second officer described CBT-informed practices as such:

I find it a useful tool for risk factors and how to talk to your offender. It's tangible. It can help them curb recidivism if we target them. This is a tool... We can better understand this thinking pattern, and help them get better jobs... They think they can outsmart the probation officers, outsmart the system. Knowing this can help you better help them. I like having the structure and guidance.

The same officer suggested that CBT should be used more consistently, while another lamented that they lack sufficient time to fully embrace CBT when working with clients, explaining how “ officers will do individual-level skills, but it's not at the same level of CBT. When you have 3050 high-risk cases, they take up so much time."

\section{Moral Reconation Therapy (MRT)}

Officers who utilized MRT with their clients had mixed views regarding its efficacy, emphasizing that it worked well in some cases but not all. One officer posited, "It seems to make a difference, but not in sovereign citizens because their beliefs are so integrated and they aren't usually violent. For beliefs that are directed toward other people and not laws, MRT has 
made a difference, it makes them take a different look at their internal motivations." The principal issue identified with MRT was that it is time-consuming, particularly when run inhouse rather than by external providers. However, some officers found that they struggled to find high-quality external providers who were willing to work with extremist populations. One interviewee explained, "I ran the MRT group and I loved it. I got to see my offenders and other offenders more often. When we transitioned to outsourcing the therapy, the contractors were less savvy with this population... They don't see the signs and there are some things they don't pick up on." Some officers worried about the composition of MRT groups, noting the danger of mixing high-risk and low-risk offenders, and extremists with other types of offenders. One interviewee described the tradeoff of creating MRT groups exclusively for extremists - they might work well, but might also lead to recruitment of experienced violent extremists by extremist groups or gangs. "They network better than we do," he said.

\section{Individual counseling}

Officers described individual counseling as an effective treatment option for extremist clients for two reasons: because "they may not feel comfortable sharing in a group environment" and because their ideology is "way too extreme for a group setting." One officer thought of individual counseling as a necessary support to "keep [the client] on track." As mentioned above, though, there are sometimes challenges both in finding qualified mental health practitioners to work with this population, and in collaborating with mental health practitioners, which can complicate the case management process. That said, a number of officers noted that telehealth options that have arisen in response to the COVID-19 pandemic have broadened client access to mental health resources, which has been especially helpful in rural districts where resources are limited. Officers also indicated that inconsistent access to psychotropic medications, and a lack 
of inpatient resources, both complicate case management. One interviewee mentioned, for example, that a client might receive one psychotropic medication while in prison, but might not have access to it upon release.

Using a scale ranging from 1 (counterproductive) to 5 (very helpful) to indicate the level of usefulness of different types of services, the officers we surveyed indicated that job training was the most useful (4.1), followed by substance abuse treatment (4.1) and mental health treatment using CBT (4) and MRT (3.9). Figure 3 below presents the rating of the survey respondents across a variety of services.

Figure 3: Federal POs' assessment of the helpfulness of programs in reintegrating extremist offenders

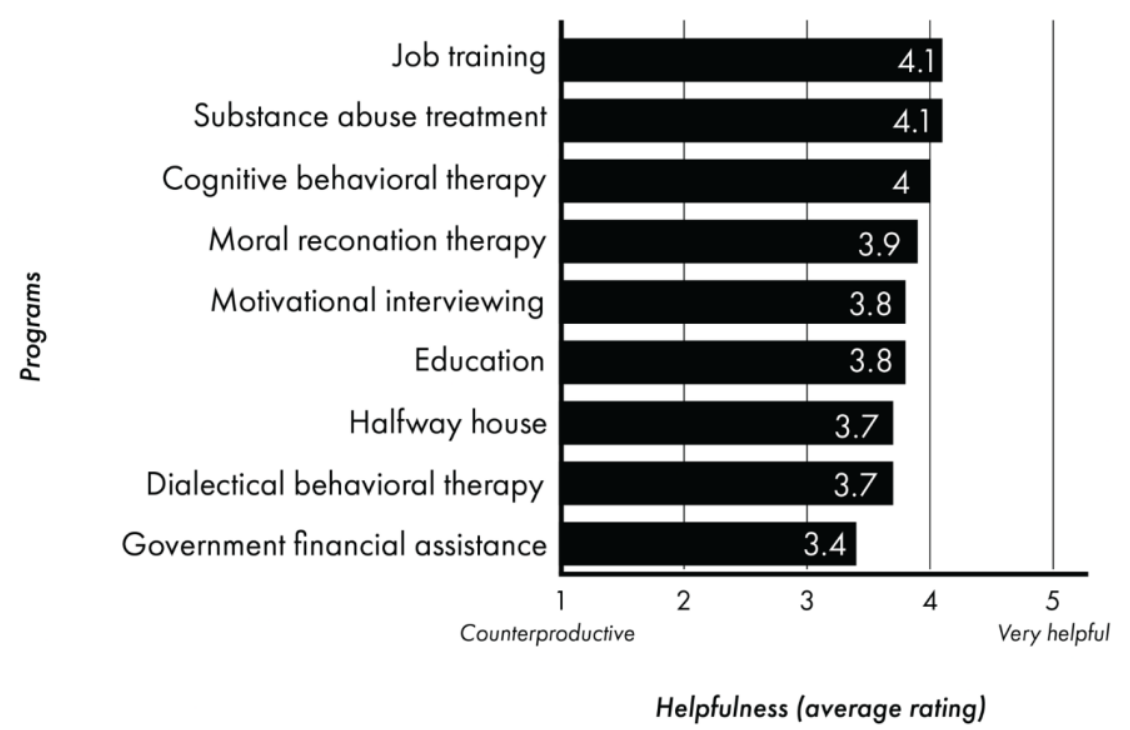

\subsection{Case Outcomes}

\subsubsection{Barriers to reintegration and protective factors}

Interviewees listed a wide variety of barriers to reintegration, focusing in particular on issues such as finding and maintaining employment; substance abuse; continued involvement 
with extremist networks and ideologies; and mental health issues. Interviewees also viewed prosocial relationships as critically important to the client's successful reintegration, with one officer explaining, "If they don't have a safety net they might give out and go back to old methods. I don't know that I could speak to somebody that was still radicalized and sway them." Employment issues stemmed from concerns regarding stigma (given their criminal background and association with terrorist groups), immigration status, and skillset. With regard to sustained extremist ties, one officer identified the issue as one of "negative peer association. Guys feel emotional stress about their peers, and are pulled between their communities and the straight and narrow." Officers cited these ties as putting their clients at risk of reengaging with both criminal behaviors and extremist ideologies. One interviewee, when describing a client, said that they "think he had underlying beliefs there. He reconnected with other members when he was out and they would lead him back towards the ideology."

The officers responding to the survey reported that for both extremists and nonextremists, a history of violent behaviors or having family/friends associated with criminal activities, were the most important barriers to reintegration (74\% rating as very important or important). Officers believed that the next most important barriers were a lack of social support (66\%), a history of substance abuse (62\%), lack of education and job skills (53\%), difficulty finding employment (52\%), restricted opportunities (51\%), lack of housing (48\%), lack of mental health services (45\%), stigma associated with a criminal past (37\%), and a lack of health insurance or health services (34\%).

\subsubsection{Defining recidivism}


There was no clear consensus among the federal probation officers interviewed on the perceived level of recidivism for violent extremist offenders. ${ }^{23}$ Nor was there consensus on whether the term would refer to a reengagement with terrorist activity or with general criminal activity. Finally, no officers provided firm numbers to support their assessments of recidivism in this population. One officer estimated that, based on his experience in managing these cases, approximately 2 out of 10 violent extremist offenders recidivate and end up back in prison (though the officer did not specify what types of offenses resulted in this return to prison), while another suggested that "most cases go back on violations" (implying that they return to prison during the period of their probation for a range of offenses not necessarily related to violent extremist activities). These officers, though, were the exception, as few gave estimates of specific recidivism rates. However, multiple officers expressed the view that violent extremist offenders recidivate frequently without providing an estimated rate of recidivism.

\subsubsection{Defining success}

The officers that defined success characterized it as termination of probation without revocation or rearrest. Officers had varying responses regarding whether ideological transformation was necessary to define a case as "successful"; some focused more on clients' actions than beliefs, while others stressed the importance of clients recognizing the harm caused by acting on extremist beliefs. One officer provided a holistic definition of success by stating, "The best outcomes are when we can actually help individuals so that when they leave our doors they are good citizens and supporting their families. Hopefully they don’t come back."

\footnotetext{
${ }^{23}$ The term "recidivism" is poorly defined in the literature on this topic, and can refer to a range of activities including, but not limited to: a new conviction for a terrorism-related crime, a new conviction for a non-terrorismrelated crime, or further involvement with a terrorist group that does not result in a conviction.
} 
Others discussed possible indicators of success. One officer noted that a case "was a success because [the client] was not associating with negative influences... No drugs, no drinking in excess, has a child." Another interviewee emphasized that a successful case would involve a client who was "very honest and very willing to speak about what [they] did. [They showed] up to appointments and [checked] in with [the officer]." A client's willingness to cooperate with law enforcement, particularly the FBI, was also cited as an indicator of success. The officers who used a broader definition of success did occasionally mention successful termination of probation, with one officer mentioning both successful probation termination and life changes such as supporting one's family. One officer noted the difficulty of defining what it would mean for a case to be resolved successfully: "But how do you assess success with a violent, antisocial [client]? Reductions in bad behavior? When they call me back? To me the biggest compliment is when I have to revoke someone and they ask for me back. I know this isn't success in a traditional sense, but they know I'm going to help them and help the community." This perspective highlights the importance of the officer-client relationship, presenting it as an indicator of success even in the face of recidivism.

\section{Discussion}

The most important findings from the federal probation officer interviews and survey include the following:

- Officers were disappointed by the lack of mental health practitioners trained — or even willing-to work with extremists. 
- Officers were dissatisfied with the PCRA as a risk evaluation tool for this population, but only one officer had tried other risk evaluation tools.

- Officers were persuaded that the recidivism rate for probationers convicted of terrorismrelated crimes was higher than the rate for offenders convicted of non-ideological crimes.

- Officers emphasized that their relationship with former offenders, and the rapport they were able to establish, was critically important to a good outcome.

Each of these points will be discussed in greater detail below.

\subsection{Mental Illness and Lack of Available Therapy}

The Bureau of Justice Statistics reported in 2005 that more than half of all prison and jail inmates had experienced a mental health problem in the previous 12 months; ${ }^{24}$ this proportion is more than twice as high as the CDC's reported rate for the general US population. ${ }^{25}$ Moreover, while federal prisons are mandated by policy to provide mental health services to inmates, less than one in four federal inmates with a mental disorder receive treatment after admission. ${ }^{26}$

\footnotetext{
${ }^{24}$ Doris J. James and Lauren E. Glaze, "Mental Health Problems of Prison and Jail Inmates," Bureau of Justice Statistics Special Report (September 2006): 12; Josiah D. Rich et al., "How Health Care Reform Can Transform the Health of Criminal Justice-Involved Individuals," Health Affairs (Project Hope) 33, no. 3 (March 2014): 462-467, https://doi.org/10.1377/hlthaff.2013.1133. The existence of mental health problems was assessed via interviews with inmates, and was based on symptoms specified in the Diagnostic and Statistical Manual of Mental Disorders (DSMIV), clinical diagnosis, or treatment by a mental health professional (yielding a higher prevalence of mental illness than is reported by clinicians working in prisons).

25 "About Mental Health," Centers for Disease Control and Prevention, November 23, 2021, https://www.cdc.gov/mentalhealth/learn/index.htm; U.S. Department of Health and Human Services, Substance Abuse and Mental Health Services Administration, Key Substance Use and Mental Health Indicators in the United States: Results from the 2019 National Survey on Drug Use and Health, by Beth Han, HHS Publication No. PEP2007-01-001, NSDUH Series H-55 (Rockville, MD: Center for Behavioral Health Statistics and Quality, 2019): 44.

${ }^{26}$ James and Glaze, "Mental Health Problems of Prison," 12.
} 
Additionally, although $70-85 \%$ of state prisoners are in need of substance abuse treatment, researchers estimate that only $13 \%$ receive care. ${ }^{27}$ To our knowledge, there are no studies focused specifically on the mental health status of violent extremists in U.S. custody or on probation.

Recent research has shown that lone-actor terrorists have a higher rate of mental illness than the general population, though there is no evidence to suggest that this finding applies to members of terrorist groups.$^{28}$ However, there are several challenges to studying the mental fitness of terrorist populations that may threaten the validity of these findings. First, some mentally ill perpetrators may not seek help and may remain undiagnosed, which could lead to undercounting of some mental illnesses. Second, researchers are sometimes forced to rely on press reporting to determine the mental health status of extremists, which is not a reliable source of a clinical diagnosis. Third, even when researchers get access to pretrial psychiatric evaluations, expert witnesses for the prosecution have an incentive to find a perpetrator fit to stand trial, while the defense may be motivated to find a perpetrator unfit. Fourth, because the number of terrorists is relatively low, researchers often work with imperfect datasets (combining data on terrorists in different eras and geographies). And fifth, statistics indicating low levels of mental illness, either in the general population or among extremist groups, may be a reflection of

\footnotetext{
${ }^{27}$ Rich et al., "How Health Care Reform Can Transform the Health of Criminal Justice-Involved Individuals."

${ }^{28}$ Paul Gill, John Horgan, and Paige Deckert, "Bombing Alone: Tracing the Motivations and Antecedent Behaviors of Lone-Actor Terrorists," Journal of Forensic Sciences 59, no. 2 (2014): 425-435, https://doi.org/10.1111/15564029.12312; Jeff Gruenewald, Steven Chermak, and Joshua D. Freilich, "Distinguishing Loner Attacks from Other Domestic Extremist Violence: A Comparison of Far-Right Homicide Incident and Offender Characteristics," Criminology \& Public Policy 12, no. 1 (2013): 65-91, https://doi.org/10.1111/1745-9133.12008; Emily Corner and Paul Gill, "A False Dichotomy? Mental Illness and Lone-Actor Terrorism," Law and Human Behavior 39, no. 1 (February 2015): 23-34, https://doi.org/10.1037/lhb0000102.
} 
exogenous factors, such as cultural or religious aversion to therapy or a shortage of mental health professionals. $^{29}$

While many clients of US probation officers are not lone actors in the strictest sense, they fall on what Borum, Fein, and Vossekuil call the continuum of loneness. The continuum of loneness exists along three dimensions: 1) independence of the terrorist's activity, a measure of whether the offender planned and executed the attack with or without assistance from a member of a violent extremist group; 2) autonomy of decision-making, a measure of whether the offender received personal instruction from a member of a violent extremist group on which targets to attack from a member of a violent extremist group; and 3) motivation, a measure of whether the offender communicated a clear political, social, or ideologically motivated grievance. ${ }^{30}$ Thus while Corner, Gill, and Mason suggest that group actors are mentally healthier than the general population, there is reason to be doubtful of this finding beyond the concerns raised above. ${ }^{31}$ In the U.S. context, it may not be possible to split the terrorist population into lone actors (found to be more mentally ill than the general population) and group actors (found to be less mentally ill than the general population); many, instead, fall somewhere on the loneness continuum. ${ }^{32}$ As just one recent example, political scientist Robert Pape found that of the 654 arrests made following the attack on the U.S. capitol on January 6th, 2021, 86\% were unaffiliated with previously identified extremist groups, but they nonetheless acted in support of at least one ideology ("stop

\footnotetext{
${ }^{29}$ Ronald Kessler and T. Bedirhan Üstün, The WHO World Mental Health Surveys: Global Perspectives on the Epidemiology of Mental Disorders (Cambridge: Cambridge University Press, 2008).

${ }^{30}$ Randy Borum, Robert Fein, and Bryan Vossekuil, "A Dimensional Approach to Analyzing Lone Offender Terrorism," Aggression and Violent Behavior 17, no. 5 (2012): 389-96, https://doi.org/10.1016/j.avb.2012.04.003.

${ }^{31}$ Emily Corner, Paul Gill, and Oliver Mason, "Mental Health Disorders and the Terrorist: A Research Note Probing Selection Effects and Disorder Prevalence," Studies in Conflict \& Terrorism 39, no. 6 (June 2, 2016): 560-568, https://doi.org/10.1080/1057610X.2015.1120099.

${ }^{32}$ Corner, Gill, and Mason, "Mental Health Disorders and the Terrorist."
} 
the steal." $)^{33}$ In short, they were neither lone actors not group members. The continuum of loneness thus complicates the lone actors/group member taxonomy, and challenges follow-on suppositions about mental health among extremists that may inform policies regarding the need for mental health providers qualified to serve this population.

It is worth noting that several mental disorders have been linked to violence and criminality. While the probability of committing an act of violence is higher for people with severe mental illness (such as schizophrenic, bipolar disorder or major depressive disorder), it is only significantly higher for those with co-occurring substance abuse or dependency. ${ }^{34}$ This correlation adds greater weight to the concerns of some probation officers in our sample, who noted that professional treatment for their clients' addiction and substance abuse is often hard to find. Furthermore, the single criminal recidivist in our database experienced both severe mental illness and a substance abuse disorder. He complained that he was not treated for these disorders until his criminal recidivation, in part due to difficulties in finding a psychiatrist who was willing to work with him and availability of insurance coverage. In 2013, offenders released from prison became eligible for Medicaid under the Affordable Care Act. ${ }^{35}$ Although efforts have been underway for years to require mental health parity in insurance coverage, exceptions are common. Most importantly in regard to released offenders, parity is not required under

\footnotetext{
${ }^{33}$ Robert A. Pape et al., "American Face of Insurrection," Chicago Project on Security and Threats (January 5, 2022): 34.

34 Eric B. Elbogen and Sally C. Johnson, "The Intricate Link Between Violence and Mental Disorder: Results From the National Epidemiologic Survey on Alcohol and Related Conditions," Archives of General Psychiatry 66, no. 2 (2009): 152-161, https://doi.org/10.1001/archgenpsychiatry.2008.537.

${ }^{35}$ Michael Ollove, "Ex-Felons Are About to Get Health Coverage," The Pew Charitable Trusts, April 5, 2013 , https://www.pewtrusts.org/en/research-and-analysis/blogs/stateline/2013/04/05/exfelons-are-about-to-get-healthcoverage. "The expansion of Medicaid, a key provision of the health care reform law, is the main vehicle for delivering health insurance to former prisoners." See also Josiah D. Rich et al., "How Health Care Reform Can Transform the Health of Criminal Justice-Involved Individuals."
} 
Medicaid. ${ }^{36}$ That means that outpatient mental health coverage may not be covered for released offenders, unless the state parity requirement is higher than the federal requirement (in which case state laws take precedence). ${ }^{37}$ This is precisely the problem that the criminal recidivist, referred to above, faced upon his release: the state where he was living at the time did not require mental-health parity.

A shortage of U.S.-based psychiatrists and other mental health professionals has been observed for years, even before the COVID-19 pandemic. ${ }^{38}$ For instance, the Health Resources and Services Administration (HRSA) estimated a shortage of about 40,000 psychiatrists in 2016, and noted that this shortfall may persist through $2050 .{ }^{39}$ Shortages have also been observed and predicted for other types of mental health professionals; in 2021, HRSA found that an additional 6,989 mental health practitioners are necessary to satisfy unmet need across the U.S. ${ }^{40}$ In addition, according to former extremists, probation officers, and NGO-based interventionists interviewed or surveyed for this project, there is a paucity of clinicians willing or trained to work with an extremist population. As noted in the results section, officers expressed concern about the difficulty of finding qualified mental health practitioners to work with their clients.

\footnotetext{
36 "What is Mental Health Parity?," National Alliance on Mental Illness, accessed February 5, 2022, https://www.nami.org/Your-Journey/Individuals-with-Mental-Illness/Understanding-Health-Insurance/What-isMental-Health-Parity.

37 "What is Mental Health Parity?"

${ }^{38}$ U.S. Department of Health and Human Services, Health Resources and Services Administration, Bureau of Health Workforce, National Projections of Supply and Demand for Selected Behavioral Health Practitioners: 2013-2025 (Rockville: National Center for Health Workforce Analysis, 2016): 35; U.S. Department of Health and Human Services (HHS), Health Resources and Services Administration, Bureau of Health Workforce, Behavioral Health Workforce Projections, 2016-2030: Psychiatrists (Adult), Child and Adolescent Psychiatrists (2019): 3.

${ }^{39}$ HHS, Behavioral Health Workforce Projections, 2016-2030, 3; Anand Satiani et al., "Projected Workforce of Psychiatrists in the United States: A Population Analysis," Psychiatric Services 69, no. 6 (June 1, 2018): 710-713, https://doi.org/10.1176/appi.ps.201700344.

40 "Shortage Areas," Health Resources and Services Administration, January 30, 2022, accessed January 31, 2022, https://data.hrsa.gov/topics/health-workforce/shortage-areas.
} 


\subsection{Post Conviction Risk Assessment and Other Risk-Evaluation Tools}

The PCRA is a risk-evaluation and management instrument developed by the Administrative Office of the U.S. Courts to improve the effectiveness and efficiency of postconviction supervision. Utilizing the PCRA enables officers to measure changes in recidivism risk over time, estimate the likelihood of adverse outcomes, and make informed decisions about what types of correctional interventions to implement in order to reduce reoffending behavior. ${ }^{41}$ The PCRA has been evaluated and can predict the likelihood that a typical offender will recidivate with relatively strong accuracy ${ }^{42}$ However, the PCRA was not developed for extremist offenders, who are widely assumed to have different vulnerabilities and criminogenic needs. ${ }^{43}$ For especially dangerous offenders, probation officers are allowed to override PCRA results through two different methods: policy overrides and discretionary overrides. Policy overrides are available when the offender is in a specific offender category, such as sex offenders, persistently violent offenders, offenders with severe mental illness, and youthful offenders with extensive criminal histories. ${ }^{44}$ Discretionary overrides are used when the offender does not fall into a specified category, but the officer nonetheless believes that more intensive

\footnotetext{
41 "Post Conviction Risk Assessment," United States Courts, last accessed March 1, 2022, https://www.uscourts.gov/services-forms/probation-and-pretrial-services/supervision/post-conviction-riskassessment; Cohen, Pendergast, and VanBenschoten, "Examining Overrides of Risk Classifications"; Lowenkamp, Holsinger, and Cohen, "PCRA Revisited." The PCRA is an actuarial risk assessment tool, which is considered to be less flexible and potentially inferior to structured professional judgment (SPJ). But SPJ instruments, such as the ERG 22+ discussed in the text, require a great deal more officer training. Unlike first generation actuarial assessment tools, the PCRA incorporates both static risk factors (such as criminal history), and dynamic ones (such as current drug use or current associations), which are amenable to change as a result of interventions.

${ }^{42}$ A statistical analysis of PCRA results for over 100,000 offenders revealed a range of AUC-ROC values between 0.70 and 0.77 , indicating the PCRA's reliability and validity. See Lowenkamp, Holsinger, and Cohen, "PCRA Revisited."

${ }^{43}$ Liesbeth van der Heide, Marieke van der Zwan, and Maarten van Leyenhorst, "The Practitioner's Guide to the Galaxy - A Comparison of Risk Assessment Tools for Violent Extremism," International Centre for CounterTerrorism (September 9, 2019): 3, https://icct.nl/publication/the-practitioners-guide-to-the-galaxy-a-comparison-ofrisk-assessment-tools-for-violent-extremism/. See also John Monahan, "The Individual Risk Assessment of Terrorism," Psychology, Public Policy and Law 18, no. 2 (2012): 167-202; Randy Borum, “Assessing Risks for Terrorism Involvement," Journal of Threat Assessment and Management 2, no. 2 (2015): 63-87. Cited in van der Heide, van der Zwan, and van Leyenhorst.

${ }^{44}$ Cohen, Pendergast, and VanBenschoten, "Examining Overrides of Risk Classifications."
} 
supervision is required. ${ }^{45}$ Many of the officers in our study expressed discomfort with the results of PCRA for their extremist clients, and chose to put their extremist offenders into a higher risk category. It is worth noting that overriding the PCRA occurs with some frequency: as indicated in a 2010 study of nearly 60,000 offenders in federal supervision, the PCRA was overridden for nearly 10 percent of offenders under federal supervision. ${ }^{46}$ As is the case for many extremist offenders under supervision, almost all of these overrides placed offenders into a higher risk category than was designated by the PCRA. Extensive research on professional overrides has found that offenders with upward overrides have reoffended at rates predicted by their original overridden assessment rather than the adjusted, higher ones. ${ }^{47}$ It is possible, however, that the more intense supervision allowed because of the overrides is what led to the lower-than-expected recidivism rate.

Extremist-specific risk-evaluation tools are widely used outside the United States. A literature review by the International Centre for Counter-Terrorism identified 15 risk-assessment tools designed for violent extremism, seven of which are more commonly used. ${ }^{48}$ Two of them appear to be dominant: ${ }^{49}$ the Extremist Risk Guidance (ERG-22+) and the Violent Extremist Risk Assessment - Consultative Version 2, Revised (VERA-2R). These two instruments, which are based on risk factors identified by terrorism researchers, have been improved over time. ${ }^{50}$

\footnotetext{
${ }^{45}$ Cohen, Pendergast, and VanBenschoten, "Examining Overrides of Risk Classifications."

${ }^{46}$ Cohen, Pendergast, and VanBenschoten, "Examining Overrides of Risk Classifications."

${ }^{47}$ Cohen, Pendergast, and VanBenschoten, "Examining Overrides of Risk Classifications."

${ }^{48}$ van der Heide, van der Zwan, and van Leyenhorst, "The Practitioner's Guide to the Galaxy."

${ }^{49}$ Martine Herzog-Evans, "A Comparison of Two Structured Professional Judgment Tools for Violent Extremism and Their Relevance in the French Context," European Journal of Probation 10, no. 1 (2018): 3-27, https://journals.sagepub.com/doi/10.1177/2066220317749140.

${ }^{50}$ For the importance of including protective factors, see John Horgan, "Disengaging from Terrorism," in The Faces of Terrorism: Multidisciplinary Perspectives, ed. David Canter (Malden: Wiley-Blackwell, 2009); Michael Jacobson, "Learning Counter-Narrative Lessons from Cases of Terrorist Dropouts," in Countering Violent Extremist Narratives (The Hague: National Coordinator for Counterterrorism, 2010); Borum, “Assessing Risk for Terrorism Involvement." Cited in RTI International, "Countering Violent Extremism: The Use of Assessment Tools for Measuring Violence Risk," literature review prepared for DHS, March 2017. For the distinction between cognitive
} 
VERA-2R is only appropriate for violent extremists, whereas ERG-22+ can be used for offenders convicted for nonviolent terrorism-related crimes. This makes ERG-22+ more broadly useful because it is applicable to individuals convicted of material support. ${ }^{51}$ However, unlike the PCRA, these instruments have not yet been validated.

Validation of terrorism-specific risk-evaluation instruments poses challenges. Terrorism is rare and perpetrators are often difficult for researchers to interview, in part because the government and prisons have not made them available to researchers. This makes risk factors difficult to validate. ${ }^{52}$ While a number of risk factors have been identified in the literature, there is no consensus about which variables are most important, and no studies thus far have established a causal link between the identified risk factors and violent crimes. ${ }^{53}$ In addition, risk factors for terrorism are highly dependent on the context. For example, the risk factors making a person vulnerable to recruitment by ISIS in Syria are presumably quite different from those making a person vulnerable to recruitment by ISIS in the West. For the former, pull factors (such as war, the salaries available to militants, need to protect one's family) are likely to be most salient; whereas in the latter, push factors (mental illness, identity uncertainty, desire for a sense of purpose or dignity) may be more important than the pull of social networks, especially for those who are high on a loneness continuum..$^{54}$

and behavioral disengagement, see John Horgan, Walking Away from Terrorism, 1st ed. (New York: Routledge, 2009); John Horgan, The Psychology of Terrorism, 2nd ed. (New York: Routledge, 2014).

${ }^{51}$ Herzog-Evans, "A Comparison of Two Structured Professional Judgment Tools."

${ }^{52}$ Validation of these risk instruments often involves assessing a large group of subjects in a prison, who are then observed to see whether the predicted level of risk is in accord with how the subjects actually behave, either while they remain in prison or upon their release. This type of validation would not be possible for violent extremists due to the danger. See RTI International, "Countering Violent Extremism: The Use of Assessment Tools for Measuring Violence Risk," literature review prepared for DHS, March 2017.

${ }^{53}$ Herzog-Evans, "A Comparison of Two Structured Professional Judgment Tools for Violent Extremism."

${ }^{54}$ Borum, Fein, and Vossekuil, "A Dimensional Approach to Analyzing Lone Offender Terrorism." 
Kevin Lowry, the former Chief Probation and Pretrial Services Officer for Minnesota, warns that the absence of specialized evaluations and treatment could contribute to extremists' further radicalization and recidivism, a risk he says has already played with both jihadi and white supremacist offenders while they were under supervision. ${ }^{55}$ The District of Minnesota has had more jihadi offenders than any other district in the United States. Lowry utilized the ERG 22+ risk assessment instrument as well as programming developed by deradicalization expert Daniel Koehler. ${ }^{56}$ Based on his experience, Lowry endorses the use of the ERG 22+, together with the PTRA (Pretrial Risk Assessment) and the PCRA. He makes clear, however, that utilizing the instrument requires that officers be specially trained and that it is quite time consuming to employ. Additionally, the probation officers in our sample argued that the PCRA is more relevant to assessing risk for white supremacists than jihadis. Interviewees reported that white supremacists are more likely to have a history of engaging in "ordinary" crimes or to have substance-abuse issues, making them more like the population the PCRA was designed to evaluate. Its developers intended for the ERG 22+ to be used for any type of extremists. An evaluation of the ERG 22+ showed good inter-rater reliability, but suggested it was more reliable for jihadis than white supremacists. ${ }^{57}$ Moreover, while the ERG 22+ provides guidelines for identifying risk and needs for extremist offenders, it is not a risk prediction tool, suggesting that it should be used in combination with an instrument designed to predict recidivism. ${ }^{58}$

\footnotetext{
${ }^{55}$ Lowry, "Responding to the Challenges of Violent Extremism/Terrorism Cases," 77.

${ }^{56}$ Lowry, "Responding to the Challenges of Violent Extremism/Terrorism Cases," 77.

${ }^{57}$ Powis et al. (2019) measured the inter-rater reliability of the ERG22+ using both research and field conditions, considered research reliability and field reliability, respectively. Beverly Powis et al., "Inter-Rater Reliability of the Extremism Risk Guidelines 22+ (ERG 22+)," Ministry of Justice Analytical Series (London: Ministry of Justice, 2019), https://assets.publishing.service.gov.uk/government/uploads/system/uploads/attachment_data/file/839726/interrater-reliability-extremism-risk-guidelines.pdf. Cited in Hughes, "Calculating and Managing Risk," 45.

${ }^{58}$ Beverly Powis, Kiran Randhawa-Horne, and Darren Bishopp, "An Examination of the Structural Properties of the Extremism Risk Guidelines (ERG22+): A Structured Formulation Tool for Extremist Offenders," Terrorism and Political Violence 33, no. 6 (2021): 1141-1159, https://doi.org/10.1080/09546553.2019.1598392. Cited in Hughes, "Calculating and Managing Risk," 47. For a fascinating discussion of their developers' contradictory descriptions of
} 


\subsection{Beliefs about recidivism}

Officers in our sample were generally pessimistic about the recidivism rate for extremist offenders, but it is important to note that they were not consulting data regarding recidivism but were sharing their informed opinions (based on their professional experience). There are two issues worth noting about these estimates. First, the term "recidivism" is used to mean many different things; this inconsistency even occurs in the scientific literature, where researchers are attempting to calculate recidivism rates based on data. ${ }^{59}$ In part because the term is used so variously, including anything from a probation violation to a second conviction for a terrorismrelated crime, and because the security situations and time periods being assessed are so diverse, reported recidivism rates range from around one percent (for individuals convicted of jihadassociated crimes in the United States) to 68 percent (based on terrorist autobiographies published between 1912 and 2011). ${ }^{60}$ We should note that in our view, the extreme recidivism rates (both low and high) in these two studies are not what U.S. probation officers should expect to encounter in their client population. The low rate refers only to U.S.-incarcerated jihadi offenders, which we expect to be lower than the rate for other types of offenders in U.S. custody as U.S.-based jihadi offenders rarely have a prior criminal history. The higher rate utilized a loose definition of recidivism, counting any reengagement regardless of whether it resulted in rearrest or reconviction. It also likely oversampled leaders (who may be more committed to a

\footnotetext{
the goals of VERA 2R and ERG 22+, see Herzog-Evans, "A Comparison of Two Structured Professional Judgment Tools."

${ }^{59}$ While rigorous analyses of terrorist recidivism rates are relatively rare, a brief review of existing studies on terrorist recidivism suggested that rates are relatively low. The articles identified figures ranging from 1.6 percent to 8.3 percent. Definitions of recidivism that varied slightly across articles, but were generally centered on the belief that a previously convicted terrorist returning to terrorist activity constitutes recidivism.

${ }^{60}$ Christopher Wright, "An Examination of Jihadi Recidivism Rates in the United States," CTC Sentinel 12, no. 10 (2019): 26-31, https://ctc.usma.edu/examination-jihadi-recidivism-rates-united-states/; Mary Beth Altier, Emma Leonard Boyle, and John G. Horgan, "Returning to the Fight: An Empirical Analysis of Terrorist Reengagement and Recidivism," Terrorism and Political Violence 33, no. 4 (2019): 836860, https://doi.org/10.1080/09546553.2019.1679781.
} 
group's persistence) and included historical cases that are likely quite different from terrorism today ${ }^{61}$ Finally, it included only individuals involved with terrorist groups, whereas many of the violent extremists in U.S. prisons today are relatively high on Borum's loneness continuum. Probation officers in our sample raised a similar concern, noting that integration into a terrorist social network could increase the risk of recidivism. A final factor likely to affect recidivism rates is whether the terrorism is taking place in the context of war or in an occupied territory. For instance, a 2019 analysis of offender records provided by the Israeli Prison Service found rates of terrorist recidivism that were significantly higher than analyses of similar data types in other countries. $^{62}$

In our view, respondents' pessimistic guesses regarding the recidivism rate for their extremist clients reflect their feelings about the expected cost to society if their efforts fail. It is well known that soldiers engaged in combat can return from battle with psychological wounds, including PTSD. ${ }^{63}$ Less well covered in the literature is the extreme stress borne by personnel in non-combat roles who are tasked with protecting the population from terrorist violence. ${ }^{64}$ Probation officers bear the burden of making decisions about violent criminals that could adversely affect many lives. This is especially true when they oversee violent extremists, who may be deradicalized by the time they enter probation but, alternatively, may be attempting to disguise a continuing commitment to carry out mass-casualty attacks in what criminologists refer

\footnotetext{
61 Thomas Renard, "Overblown: Exploring the Gap Between the Fear of Terrorist Recidivism and the Evidence," CTC Sentinel 13, no. 4 (2020): 19-29, https://www.ctc.usma.edu/overblown-exploring-the-gap-between-the-fear-ofterrorist-recidivism-and-the-evidence/.

${ }^{62}$ Badi Hasisi et al., "Crime and Terror: Examining Criminal Risk Factors for Terrorist Recidivism," Journal of Quantitative Criminology 36 (2019): 449, https://doi.org/10.1007/s10940-019-09415-y.

63 Jonathan Shay, Achilles in Vietnam: Combat Trauma and the Undoing of Character (New York: Scribner, 1994). This book sparked a whole literature on combat-related PTSD.

${ }^{64}$ Ursula M. Wilder, "Inside the Inferno: Counterterrorism Professionals Reflect on their Work," Studies in Intelligence 58, no. 4 (Unclassified Extracts, 2014): 3-17, https://www.hsdl.org/?view\&did=811629. Although this article does not discuss probation officers per se, it discusses trauma among other types of non-combat-related counterterrorism professionals.
} 
to as "disguised compliance." 65 In this vein, three violent attacks (two in London and one in Austria) were carried out by terrorists who had gone through rehabilitative programming, and U.S. officials suspect that a released Guantánamo detainee is responsible for a fourth violent attack at the U.S. embassy in Yemen; government officials reportedly thought each of these individuals had been successfully deradicalized. ${ }^{66}$ Although attacks by recidivated terrorist offenders are relatively rare, they tend to receive a lot of press coverage, making the gravity of probation officers' jobs especially salient. We interpret the results of the survey questions regarding "success" and "recidivism" to mean that officers responsible for overseeing violent extremists are understandably alarmed about the risks and they should receive extra training, including on the topic of recidivism. Officers strongly endorsed the need for specialized training in both interviews and the surveys. Extra training makes sense: a 2013 literature review assessed the impact of the skill level of officers overseeing ordinary criminals, and found that high skill levels were significantly correlated with reduced recidivism rates. ${ }^{67}$

\footnotetext{
${ }^{65}$ Ian Acheson, “Are We Any Closer to Stopping the Next Usman Khan?,” The Spectator, November 2020, https://www.spectator.co.uk/article/are-we-any-closer-to-stopping-the-next-usman-khan-. ${ }_{66}$ Tanya Mehra and Julie Coleman, "Vienna Attack: The Path of a Prospective (Foreign) Terrorist Fighter," International Centre for Counter-Terrorism (November 16, 2020), https://icct.nl/publication/vienna-attack-the-pathof-a-prospective-foreign-terrorist-fighter/; Douglas Weeks, "Lessons Learned from UK Efforts to Deradicalize Terror Offenders," CTC Sentinel 14, no. 3 (March 2021), https://www.ctc.usma.edu/lessons-learned-from-u-kefforts-to-deradicalize-terror-offenders/; Rajan Basra and Peter R. Neumann, "Case Study 5: Usman Khan," in Prisons and Terrorism: Extremist Offender Management in 10 European Countries (London: International Centre for the Study of Radicalisation, 2020): 46-48, https://icsr.info/wp-content/uploads/2020/07/ICSR-Report-Prisonsand-Terrorism-Extremist-Offender-Management-in-10-European-Countries_V2.pdf; Robert F. Worth, "Freed by the U.S., Saudi Becomes a Qaeda Chief," The New York Times, January 22, 2009, https://www.nytimes.com/2009/01/23/world/middleeast/23yemen.html.

${ }^{67}$ Chris Trotter, "Reducing Recidivism Through Probation Supervision: What We Know and Don't Know from Four Decades of Research" 77, no. 2 (2013): 6, https://www.uscourts.gov/sites/default/files/77_2_7_0.pdf. Cited in Hughes, "Calculating and Managing Risk," 21.
} 


\subsection{Rapport}

Scholars have noted that the work of probation officers has evolved considerably from the original tasks of "merely tracking compliance" to the use of "case management practices that are designed to create a more therapeutic relationship between the officer and client."68 The value of today's approach is based on the theory that clients who feel that they are being treated fairly - a theme noted by federal probation officers in our interviews - are more likely to complete their probation successfully. This pattern has been attributed to a range of reasons including the possibility that positive relationships between clients and probation officers may result in clients feeling loyalty to the officer, which may decrease the likelihood of offending; increase the likelihood that a client will confide in the officer, increasing opportunities for intervention; or facilitate the client's ability to effectively communicate needs to the officer. ${ }^{69}$ Critically, scholars have demonstrated that a positive officer/client relationship is correlated with positive outcomes. One study found that client perceptions of positive rapport with a probation officer correlated with a reduced likelihood of recidivism, while client perceptions of negative rapport were associated with an increased likelihood of recidivism. ${ }^{70}$ Moreover, the article went on to note that "even for high risk offenders with negative traits, strong officer-offender relationships can be established and reduce the risk of rearrest." 71

\footnotetext{
${ }^{68}$ Leanne F. Alarid and Mark Jones, "Perceptions of Offender Satisfaction on Probation and Supervised Release with STARR Skill Sets," Federal Probation: A Journal of Correctional Philosophy and Practice 82, no 1 (June 2018): 37-54.

${ }^{69}$ Alyssa W. Chamberlain et al., "Parolee-Parole Officer Rapport: Does It Impact Recidivism?,” International Journal of Offender Therapy and Comparative Criminology 62, no. 11 (2018): 3581-3602.

${ }^{70}$ Chamberlain et al., "Parolee-Parole Officer Rapport." Patrick J. Kennealy et al., "Firm, Fair, and Caring OfficerOffender Relationships Protect Against Supervision Failure," Law and Human Behavior 36, no. 6 (2012): 496.

${ }^{71}$ Kennealy et al., "Firm, Fair, and Caring Officer-Offender Relationships," 496.
} 
At present, at least three training programs exist to teach probation officers the skills necessary to successfully cultivate the more therapeutic approach correlated with successful outcomes: Effective Practices in Community Supervision (EPICS), Strategic Training Initiative in Community Supervision (STICS), and Staff Training Aimed at Reducing Rearrest (STARR). The latter, developed by U.S. Probation and Pretrial Services in 2009, was mentioned repeatedly - and positively - by probation officers during our interviews, and a 2018 study assessing client satisfaction concluded that "most POs in these two districts [being analyzed] are properly using STARR skill sets and that clients are satisfied with their experience on supervision." 72 However, existing research raises at least two questions that merit consideration.

First, it is not clear that the STARR approach has utility for the extremist population. Empirical research has found that while moderate-risk clients supervised by STARR-trained probation officers were 50 percent less likely to recidivate, high-risk clients were not less likely to recidivate. ${ }^{73}$ Moderate risk clients with STARR-trained officers fared much better than moderate risk clients without STARR-trained officers (i.e., failure rates of 16 percent versus 32 percent) ${ }^{74}$ By contrast, there was no difference in the failure rates for high risk clients; that is, having a STARR-trained probation officer appears to have no impact on case outcome for the high risk population. This finding, moreover, held steady when the analysis was replicated using 24 months of data (instead of just 12 months of data). ${ }^{75}$

\footnotetext{
72 Alarid and Jones, "Perceptions of Offender Satisfaction."

${ }^{73}$ Charles R. Robinson et al., "A Random Study of Staff Training Aimed at Reducing Rearrest (STARR): Using Core Correctional Practices in Probation Interactions," Journal of Crime and Justice 35, no. 2 (2012): $167-188$.

${ }^{74}$ Robinson et al., "A Random Study of Staff Training Aimed at Reducing Rearrest (STARR)."

${ }^{75}$ Christopher T. Lowenkamp et al., "Diminishing or Durable Treatment Effects of STARR? A Research Note on 24-Month Re-Arrest Rates," Journal of Crime and Justice 37, no. 2 (2014): 275-283.
} 
Second, some research has found that the provision of "professional support (e.g., providing correct information)" is more powerful than the provision of "interpersonal support (e.g., listening and caring)" in decreasing reincarceration (i.e., recidivism), suggesting that professional support might be more important than rapport. ${ }^{76}$ The authors offered two potential explanations for this pattern. First, because professional support is not merely the provision of data, but the provision of data in a professional (i.e., respectful and accurate) manner, it may be the case that this category includes some features of emotional support such as being trustworthy or helpful (thus making professional support a more inclusive form of support than interpersonal support). Second, because interpersonal support can be provided by a range of contacts including friends and family, it may be the case that the impact of interpersonal support from probation officers is less significant than that of professional support (which is unique to probation officers).

\subsection{Study Limitations}

We recognize several limitations in our study design and findings, among which the most important are related to the data collection methods. First, the opinions and experiences shared in this manuscript were not derived from a representative sample of federal probation officers. As such, their experiences may not represent those of all probation officers, as those willing to take the time to participate in one-hour interviews are presumably more interested, and possibly more experienced, than those who chose not to participate. Second, the officers we interviewed were managing a wide range of extremists, ranging from offenders arrested for crimes unrelated to violent extremism (but who were known to be involved in extremist groups), to individuals

\footnotetext{
${ }^{76}$ Kyle J. Bares and Thomas J. Mowen, "Examining the Parole Officer as a Mechanism of Social Support During Reentry from Prison," Crime \& Delinquency 66, nos. 6-7 (2020): 1023-1051.
} 
arrested for serious terrorism related crimes. The results are consequently not applicable to a specific category of extremists, nor to all extremists, but reflect officers' experiences of managing a broad range of offenders who pose different levels of risk to society. Third, the semistructured interviewing technique we used does not allow us to derive conclusions about how frequently specific interventions are employed, imposing a limitation on the aggregation of results.

\section{Conclusion}

Draft of the conclusion is not yet available. 


\section{Bibliography}

“About Mental Health.” Centers for Disease Control and Prevention. November 23, 2021. https://www.cdc.gov/mentalhealth/learn/index.htm.

Acheson, Ian. “Are We Any Closer to Stopping the Next Usman Khan?” The Spectator. November 2020. https://www.spectator.co.uk/article/are-we-any-closer-to-stopping-thenext-usman-khan-.

Alarid Leanne F. and Mark Jones. "Perceptions of Offender Satisfaction on Probation and Supervised Release with STARR Skill Sets.” Federal Probation: A Journal of Correctional Philosophy and Practice 82, no 1 (June 2018): 37-54.

Altier, Mary Beth, Emma Leonard Boyle, and John G. Horgan. "Returning to the Fight: An Empirical Analysis of Terrorist Reengagement and Recidivism." Terrorism and Political Violence 33, no. 4 (2019): 836-860. https://doi.org/10.1080/09546553.2019.1679781. Anindya, Chaula Rininta. "The Deradicalisation Programme for Indonesian Deportees: A Vacuum in Coordination.” Journal for Deradicalization 18 (Spring 2019): 217-243. Azam, Zubair and Syeda Bareeha Fatima. "Mishal: A Case Study of a Deradicalization and Emancipation Program in Swat Valley, Pakistan.” Journal for Deradicalization 11 (Summer 2017): 1-29.

Bares, Kyle J. and Thomas J. Mowen. "Examining the Parole Officer as a Mechanism of Social Support During Reentry from Prison.” Crime \& Delinquency 66, nos. 6-7 (2020): 10231051.

Basra, Rajan and Peter R. Neumann. "Case Study 5: Usman Khan.” In Prisons and Terrorism: Extremist Offender Management in 10 European Countries (London: International Centre for the Study of Radicalisation, 2020): 46-48. https://icsr.info/wp- 
content/uploads/2020/07/ICSR-Report-Prisons-and-Terrorism-Extremist-OffenderManagement-in-10-European-Countries_V2.pdf.

Bastug, Mehmet F. and Ugur K. Evlek. "Individual Disengagement and Deradicalization Pilot Program in Turkey: Methods and Outcomes.” Journal for Deradicalization 8 (Fall 2016): $25-45$.

Beaghley, Sina, Todd C. Helmus, Miriam Matthews, Rajeev Ramchand, David Stebbins, Amanda Kadlec, and Michael A. Brown. "Development and Pilot Test of the RAND Program Evaluation Toolkit for Countering Violent Extremism." RAND Corporation (2017).

Borum, Randy. “Assessing Risks for Terrorism Involvement.” Journal of Threat Assessment and Management 2, no. 2 (2015): 63-87.

Borum, Randy, Robert Fein, and Bryan Vossekuil. “A Dimensional Approach to Analyzing Lone Offender Terrorism." Aggression and Violent Behavior 17, no. 5 (2012): 389-396. https://doi.org/10.1016/j.avb.2012.04.003.

Bowers, Barbara, Lauren W. Cohen, Amy E. Elliot, David C. Grabowski, Nancy W. Fishman, Siobhan S. Sharkey, Sheryl Zimmerman, Susan D. Horn, and Peter Kemper. "Creating and Supporting a Mixed Methods Health Services Research Team." Health Services Research 48, no. 6 part II (2013), doi:10.1111/1475-6773.12118.

Chamberlain, Alyssa W., Matthew Gricius, Danielle M. Wallace, Diana Borjas, and Vincent M. Ware. “Parolee-Parole Officer Rapport: Does It Impact Recidivism?” International Journal of Offender Therapy and Comparative Criminology 62, no. 11 (2018): 35813602. 
Cohen, Thomas H., Bailey Pendergast, and Scott W. VanBenschoten. "Examining Overrides of Risk Classifications for Offenders on Federal Supervision." Federal Probation: A Journal of Correctional Philosophy and Practice 80, no. 1 (June 2016). https://www.uscourts.gov/federal-probation-journal/2016/06/examining-overrides-riskclassifications-offenders-federal.

Corner, Emily and Paul Gill. "A False Dichotomy? Mental Illness and Lone-Actor Terrorism.” Law and Human Behavior 39, no. 1 (February 2015): 23-34. https://doi.org/10.1037/lhb0000102.

Corner, Emily, Paul Gill, and Oliver Mason. "Mental Health Disorders and the Terrorist: A Research Note Probing Selection Effects and Disorder Prevalence." Studies in Conflict \& Terrorism 39, no. 6 (June 2, 2016): 560-568. https://doi.org/10.1080/1057610X.2015.1120099.

Decker, Scott H. and David C. Pyrooz. "The Imprisonment-Extremism Nexus: Continuity and Change in Activism and Radicalism Intentions in a Longitudinal Study of Prisoner Reentry.” PLoS ONE 15, no. 11 (2020), https://doi.org/10.1371/journal.pone.0242910.

Elbogen, Eric B. and Sally C. Johnson. "The Intricate Link Between Violence and Mental Disorder: Results From the National Epidemiologic Survey on Alcohol and Related Conditions." Archives of General Psychiatry 66, no. 2 (2009): 152-161. https://doi.org/10.1001/archgenpsychiatry.2008.537.

"Evaluability Assessment and Development of Psychological and Behavioral Health Approaches to Prevent Terrorism and Facilitate Reintegration of Violent Extremists." National Institute of Justice. October 22, 2021. https://nij.ojp.gov/funding/awards/15pnij-21-gg02727-domr. 
Gill, Paul, John Horgan, and Paige Deckert. "Bombing Alone: Tracing the Motivations and Antecedent Behaviors of Lone-Actor Terrorists." Journal of Forensic Sciences 59, no. 2 (2014): 425-435. https://doi.org/10.1111/1556-4029.12312.

Gruenewald, Jeff, Steven Chermak, and Joshua D. Freilich. "Distinguishing Loner Attacks from Other Domestic Extremist Violence: A Comparison of Far-Right Homicide Incident and Offender Characteristics." Criminology \& Public Policy 12, no. 1 (2013): 65-91. https://doi.org/10.1111/1745-9133.12008.

Hasisi, Badi, Tomer Carmel, David Weisburd, and Michael Wolfowicz. "Crime and Terror: Examining Criminal Risk Factors for Terrorist Recidivism." Journal of Quantitative Criminology 36 (2019): 449-472. https://doi.org/10.1007/s10940-019-09415-y.

Herzog-Evans, Martine. “A Comparison of Two Structured Professional Judgment Tools for Violent Extremism and Their Relevance in the French Context." European Journal of Probation 10, no. 1 (2018): 3-27. https://journals.sagepub.com/doi/10.1177/2066220317749140.

Horgan, John. "Disengaging from Terrorism." In The Faces of Terrorism: Multidisciplinary Perspectives, edited by David Canter (Malden: Wiley-Blackwell, 2009).

Horgan, John. The Psychology of Terrorism. 2nd ed. (New York: Routledge, 2014).

Horgan, John. Walking Away from Terrorism. 1st ed. (New York: Routledge, 2009). Hughes, Diána R. “Calculating and Managing Risk: Risk Assessment Tools for Violent and Non-Violent Extremist Offenders." Submitted in partial fulfillment of the requirements for the degree of Master of International Affairs with a Specialization in Security Studies, Pardee School of Global Studies, Boston University, April 2021. 
Jacobson, Michael. "Learning Counter-Narrative Lessons from Cases of Terrorist Dropouts.” In Countering Violent Extremist Narratives (The Hague: National Coordinator for Counterterrorism, 2010).

James, Doris J. and Lauren E. Glaze. "Mental Health Problems of Prison and Jail Inmates.” Bureau of Justice Statistics Special Report (September 2006).

Kaufman-Levy, Deborah and Mary Poulin. "Evaluability Assessment: Examining the Readiness of a Program for Evaluation." Juvenile Justice Evaluation Center Program Evaluation Briefing Series, 6 (May 2003). https://www.jrsa.org/pubs/juv-justice/evaluabilityassessment.pdf.

Kennealy, Patrick J., Jennifer L. Skeem, Sarah M. Manchak, and Jennifer Eno Louden. "Firm, Fair, and Caring Officer-Offender Relationships Protect Against Supervision Failure." Law and Human Behavior 36, no. 6 (2012): 496-505.

Kessler, Ronald and T. Bedirhan Üstün. The WHO World Mental Health Surveys: Global Perspectives on the Epidemiology of Mental Disorders (Cambridge: Cambridge University Press, 2008).

Koehler, Daniel. "How and Why We Should Take Deradicalization Seriously." Nature Human Behaviour 1 (2017): 1-4.

Korn, Judy. "European CVE Strategies from a Practitioner's Perspective." Annals of the American Academy of Political and Social Science 668, no. 1 (2016): 180-197.

LaFree, Gary, Bo Jiang, and Lauren C. Porter. "Prison and Violent Political Extremism in the United States.” Journal of Quantitative Criminology 36 (2020): 473-498. 
Lowenkamp, Christopher T., Alexander M. Holsinger, Charles R. Robinson, and Melissa Alexander. "Diminishing or Durable Treatment Effects of STARR? A Research Note on 24-Month Re-Arrest Rates.” Journal of Crime and Justice 37, no. 2 (2014): 275-283.

Lowenkamp, Christopher T., Alexander M. Holsinger, and Thomas H. Cohen. "PCRA Revisited: Testing the Validity of the Federal Post Conviction Risk Assessment (PCRA).” Psychological Services 12, no. 2 (2015): 149-157. https://doi.org/10.1037/ser0000024. Lowry, Kevin D. "Responding to the Challenges of Violent Extremism/Terrorism Cases for United States Probation and Pretrial Services.” Journal for Deradicalization 17 (Winter 2018/2019): 28-88.

Mehra, Tanya and Julie Coleman. "Vienna Attack: The Path of a Prospective (Foreign) Terrorist Fighter.” International Centre for Counter-Terrorism. November 16, 2020. https://icct.nl/publication/vienna-attack-the-path-of-a-prospective-foreign-terroristfighter/.

Monahan, John. “The Individual Risk Assessment of Terrorism.” Psychology, Public Policy and Law 18, no. 2 (2012): 167-202.

Moskalenko, Sophia and Clark McCauley. "Measuring Political Mobilization: The Distinction Between Activism and Radicalism." Terrorism and Political Violence 21, no. 2 (March 30, 2009): 239-260.

Naderi, Nader. "Prisonization.” In The Encyclopedia of Criminology and Criminal Justice, edited by Jay S. Albanese (Oxford: Blackwell Publishing Ltd., 2014), 1-5.

Ollove, Michael. "Ex-Felons Are About to Get Health Coverage." The Pew Charitable Trusts. April 5, 2013. https://www.pewtrusts.org/en/research-andanalysis/blogs/stateline/2013/04/05/exfelons-are-about-to-get-health-coverage. 
Pape, Robert A., Keven Ruby, Kyle Larson, and Sabreena Croteau. "American Face of Insurrection." Chicago Project on Security and Threats (January 5, 2022).

“Post Conviction Risk Assessment.” United States Courts. Last accessed March 1, 2022. https://www.uscourts.gov/services-forms/probation-and-pretrialservices/supervision/post-conviction-risk-assessment.

Powis, Beverly, Kiran Randhawa-Horne, and Darren Bishopp. "An Examination of the Structural Properties of the Extremism Risk Guidelines (ERG22+): A Structured Formulation Tool for Extremist Offenders." Terrorism and Political Violence 33, no. 6 (2021): 1141-1159. https://doi.org/10.1080/09546553.2019.1598392.

Powis, Beverly, Kiran Randhawa-Horne, Ian Elliott, and Jessica Woodhams. "Inter-Rater Reliability of the Extremism Risk Guidelines 22+ (ERG 22+)." Ministry of Justice Analytical Series (London: Ministry of Justice, 2019). https://assets.publishing.service.gov.uk/government/uploads/system/uploads/attachment_ data/file/839726/inter-rater-reliability-extremism-risk-guidelines.pdf.

Renard, Thomas. "Overblown: Exploring the Gap Between the Fear of Terrorist Recidivism and the Evidence." CTC Sentinel 13, no. 4 (2020): 19-29. https://www.ctc.usma.edu/overblown-exploring-the-gap-between-the-fear-of-terroristrecidivism-and-the-evidence/.

Rich, Josiah D., Redonna Chandler, Brie A. Williams, Dora Dumont, Emily A. Wang, Faye S. Taxman, Scott A. Allen, et al. "How Health Care Reform Can Transform the Health of Criminal Justice-Involved Individuals.” Health Affairs (Project Hope) 33, no. 3 (March 2014): 462-467. https://doi.org/10.1377/hlthaff.2013.1133. 
Robinson, Charles R., Christopher T. Lowenkamp, Alexander M. Holsinger, Scott VanBenschoten, Melissa Alexander, and J.C. Oleson. “A Random Study of Staff Training Aimed at Reducing Rearrest (STARR): Using Core Correctional Practices in Probation Interactions." Journal of Crime and Justice 35, no. 2 (2012): 167-188.

RTI International. “Countering Violent Extremism: The Use of Assessment Tools for Measuring Violence Risk.” Literature review prepared for DHS, March 2017.

Satiani, Anand, Julie Niedermier, Bhagwan Satiani, and Dale P. Svendsen. "Projected Workforce of Psychiatrists in the United States: A Population Analysis.” Psychiatric Services 69, no. 6 (June 1, 2018): 710-713. https://doi.org/10.1176/appi.ps.201700344.

Sestoft, Dorte, S.M. Hansen, and A.B. Christensen. "The Police, Social Services, and Psychiatry (PSP) Cooperation as a Platform for Dealing with Concerns of Radicalization.” International Review of Psychology 29, no. 4 (2017): 350-354.

Shay, Jonathan. Achilles in Vietnam: Combat Trauma and the Undoing of Character (New York: Scribner, 1994).

“Shortage Areas." Health Resources and Services Administration. January 30, 2022. Accessed January 31, 2022. https://data.hrsa.gov/topics/health-workforce/shortage-areas.

Trotter, Chris. "Reducing Recidivism Through Probation Supervision: What We Know and Don’t Know from Four Decades of Research.” Federal Probation: A Journal of Correctional Philosophy and Practice 77, no. 2 (2013). https://www.uscourts.gov/sites/default/files/77_2_7_0.pdf.

U.S. Congress. House. Committee on Appropriations. Subcommittee on the Department of Homeland Security. Targeted Violence and Terrorism Prevention. 117th Cong., 1st sess., March 24, 2021. 
U.S. Congress. Senate. Judiciary Committee. Oversight of the Federal Bureau of Investigation: The January 6 Insurrection, Domestic Terrorism, and Other Threats. 117th Cong., 1st sess., March 2, 2021.

U.S. Department of Health and Human Services. Health Resources and Services Administration. Bureau of Health Workforce. Behavioral Health Workforce Projections, 2016-2030: Psychiatrists (Adult), Child and Adolescent Psychiatrists (2019).

U.S. Department of Health and Human Services. Health Resources and Services Administration. Bureau of Health Workforce. National Projections of Supply and Demand for Selected Behavioral Health Practitioners: 2013-2025 (Rockville: National Center for Health Workforce Analysis, 2016).

U.S. Department of Health and Human Services. Substance Abuse and Mental Health Services Administration. Key Substance Use and Mental Health Indicators in the United States: Results from the 2019 National Survey on Drug Use and Health, by Beth Han. HHS Publication No. PEP20-07-01-001, NSDUH Series H-55 (Rockville, MD: Center for Behavioral Health Statistics and Quality, 2019).

U.S. Department of Justice. Federal Bureau of Investigation. Domestic Terrorism: Definitions, Terminology, and Methodology (November 2020).

U.S. Office of the Director of National Intelligence. National Counterterrorism Center. "US Homegrown Violent Extremist Recidivism Likely.” National Counterterrorism Center Current (January 24, 2017).

U.S. Office of the Director of National Intelligence, U.S. Department of Justice, and U.S. Department of Homeland Security. Unclassified Summary of Assessment on Domestic Violent Extremism (March 17, 2021). 
van der Heide, Liesbeth, Marieke van der Zwan, and Maarten van Leyenhorst. "The Practitioner's Guide to the Galaxy - A Comparison of Risk Assessment Tools for Violent Extremism.” International Centre for Counter-Terrorism (September 9, 2019). https://icct.nl/publication/the-practitioners-guide-to-the-galaxy-a-comparison-of-riskassessment-tools-for-violent-extremism/.

Weeks, Douglas. "Doing Derad: An Analysis of the U.K. System.” Studies in Conflict \& Terrorism 41, no. 7 (2018): 523-540.

Weeks, Douglas. "Lessons Learned from UK Efforts to Deradicalize Terror Offenders." CTC Sentinel 14, no. 3 (March 2021). https://www.ctc.usma.edu/lessons-learned-from-u-kefforts-to-deradicalize-terror-offenders/.

"What is Mental Health Parity?" National Alliance on Mental Illness. Accessed February 5, 2022. https://www.nami.org/Your-Journey/Individuals-with-MentalIllness/Understanding-Health-Insurance/What-is-Mental-Health-Parity.

Wilder, Ursula M. "Inside the Inferno: Counterterrorism Professionals Reflect on their Work." Studies in Intelligence 58, no. 4 (Unclassified Extracts, 2014): 3-17. https://www.hsdl.org/?view\&did=811629.

Worth, Robert F. "Freed by the U.S., Saudi Becomes a Qaeda Chief." The New York Times. January 22, 2009. https://www.nytimes.com/2009/01/23/world/middleeast/23yemen.html.

Wright, Christopher. "An Examination of Jihadi Recidivism Rates in the United States." CTC Sentinel 12, no. 10 (2019): 26-31. https://ctc.usma.edu/examination-jihadi-recidivismrates-united-states/. 